\title{
Tension pneumopericardium and pneumoperitoneum: a rare complication of pericardiocentesis
}

\author{
Gerrit Jansen, MD (1) • Linda Irmscher, MD • Rainer Borgstedt, MD • \\ Sebastian W. Rehberg, MD
}

Received: 5 May 2021/Revised: 13 May 2021 / Accepted: 13 May 2021/Published online: 28 May 2021

(C) The Author(s) 2021

\begin{abstract}
A 79-year-old man developed cardiac decompensation due to a tacrolimus-induced hemodynamically significant pericardial effusion that was relieved by subxiphoid pericardial drainage. Because of clinical deterioration twelve days after pericardiocentesis, a computed tomography (CT) scan of the thorax and abdomen was performed. The CT scan (Figure 1) revealed a large ventrally located pneumopericardium with a maximum width of $5.5 \mathrm{~cm}$ as well as displacement and compression of cardiac structures and the left upper lobe of the lung. In addition, pneumoperitoneum with large amounts of free air along the ventral abdominal wall was apparent.
\end{abstract}

G. Jansen, MD $(\varangle) \cdot$ L. Irmscher, MD · R. Borgstedt, MD .

S. W. Rehberg, MD

Department of Anesthesiology, Intensive Care, Emergency

Medicine, Transfusion Medicine, and Pain Therapy, Protestant

Hospital of the Bethel Foundation, Bielefeld University Hospital,

Campus Bielefeld-Bethel, University of Bielefeld, Bielefeld,

Germany

e-mail: Gerrit.Jansen@evkb.de
Paramediastinal minithoracotomy showed tension pneumopericardium. Laparotomy revealed a small serosal lesion of the small intestine and a perforation of the transverse colon, possibly caused by the pericardial puncture. After the therapeutic procedures, the patient recovered, gave written informed consent for publication of the complication, and was discharged from the intensive care unit after six days.

A combined pneumopericardium and pneumoperitoneum of such a size represents a rare complication of pericardiocentesis. In the case of clinical deterioration, even with a significant time delay after pericardiocentesis, it is necessary to consider this rare diagnosis. Although it is often self-limiting, fulminant and life-threatening courses also occur. In these cases, immediate decompression via re-pericardiocentesis or pericardiotomy is required. 
FIGURE 1 Computed tomography scan showing pneumopericardium $(*)$, ventrally located pneumopericardium $(*)$, displacement and compression of cardiac structures (\#) and the left upper lobe of the lung $(+)$, and pneumoperitoneum $(\S)$

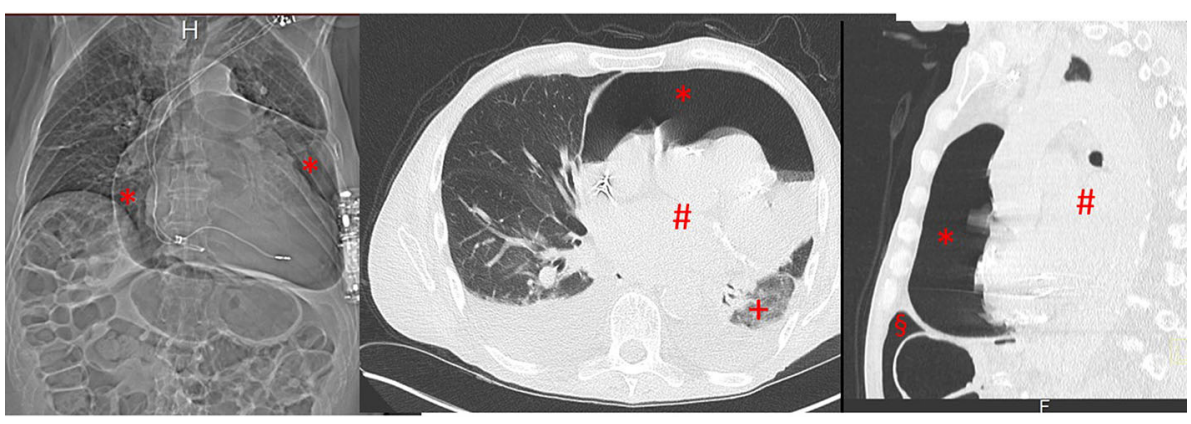

Disclosures Sebastian Rehberg is a medical advisor for Fresenius Kabi Germany and has received honoraria and travel expenses from Amomed Pharma and Orion Pharma. The remaining authors have disclosed that they do not have any conflicts of interest.

Financial statement This work was solely supported by institutional and departmental sources.

Editorial responsibility This submission was handled by Dr. Philip M. Jones, Deputy Editor-in-Chief, Canadian Journal of Anesthesial Journal canadien d'anesthésie.

Funding Open Access funding enabled and organized by Projekt DEAL.

Open Access This article is licensed under a Creative Commons
Attribution-NonCommercial 4.0 International License, which permits any non-commercial use, sharing, adaptation, distribution and reproduction in any medium or format, as long as you give appropriate credit to the original author(s) and the source, provide a link to the Creative Commons licence, and indicate if changes were made. The images or other third party material in this article are included in the article's Creative Commons licence, unless indicated otherwise in a credit line to the material. If material is not included in the article's Creative Commons licence and your intended use is not permitted by statutory regulation or exceeds the permitted use, you will need to obtain permission directly from the copyright holder. To view a copy of this licence, visit http://creativecommons.org/licenses/ by-nc/4.0/.

Publisher's Note Springer Nature remains neutral with regard to jurisdictional claims in published maps and institutional affiliations. 